This is a self-archived - parallel published version of this article in the publication archive of the University of Vaasa. It might differ from the original.

\title{
Using choir conducting to improve leadership practice
}

\author{
Authors: $\quad$ Koivunen, Niina; Parush, Tamar \\ Title: $\quad$ Using choir conducting to improve leadership practice \\ Year: $\quad 2019$ \\ Version: Accepted manuscript \\ Copyright Palgrave Macmillan
}

Please cite the original version:

Koivunen, N. \& Parush, T., (2019). Using choir conducting to improve leadership practice. In E. Antonacopoulou \& S.S. Taylor(Ed). Sensuous Learning for Practical Judgment in Professional Practice : Volume 1: Arts-based Methods (71-96). London: Palgrave Macmillan. 


\section{Niina Koivunen and Tamar Parush}

\section{Using choir conducting to improve leadership practice}

"It is becoming more and more important in any sort of leadership that you really understand who you are leading, and that you build up this relationship not only intellectually but also with a very embodied and passionate part of your deed as a leader, and that you get people on board." (Peter Hanke, video clip 3.)

"Putting yourself at stake as a human being, touching other people's aspirations, skills, inspiring them, giving them something they did not know they possessed, lifting up a complete organization with your actions." (Peter Hanke, video clip 2.)

This chapter describes and discusses how a particular form of artistic performance - that of choir conducting - can serve as a method of learning leadership. Earlier research on artistic methods or art-based interventions has shown how such methods can bring about profound organizational transformation and learning (Austin and Devin, 2003; Darsø, 2004; Taylor and Ladkin, 2009; Barry and Meisiek, 2010; Springborg, 2012; Parush and Koivunen, 2014; Johansson Skoldberg, Woodilla and Berthoin Antal, 2015). Another body of literature, that of embodiment and aesthetic ways of knowing, demonstrates how sense perception and emotions and feelings of the body play an important part in acquiring new knowledge (Koivunen and Wennes, 2011; Strati, 1999; Taylor and Hansen, 2005; Warren, 2008). Our study draws on both of these fields.

One of the practices in which experiential learning, and art-based methods in particular, have become especially common in recent years is leadership development (Nissley, 2002; Springborg, 2012; Taylor and Ladkin, 2009). It is widely accepted that leadership development is much more than choosing a leadership theory and introducing its abstract principles to participants (Day et al. 2014). Rather, this intervention seeks to help participants in developing their leadership identity (Kark, 2011) and perfecting their "self-as-leader" (Sinclair, 2011), and hence involves profound reflection and working on the self, in all its uniqueness and concreteness. Experiential learning and art-based methods are particularly 
useful for this purpose. Not only do they bring to the field of leadership development embodied, sensuous and aesthetic forms of learning, they also promote the perception of leadership as an art, which cannot be reduced to abstract, rational and cerebral principles. One of the most enticing images linking leadership and art is that of the musical conductor - an artist who is also a powerful, highly visible leader. And indeed, our focus in this chapter is on leadership development workshops that apply and embody precisely this image.

More specifically, we examine leadership development workshops that are designed and facilitated by professional Danish choir conductor Peter Hanke, who has a long experience in educating managers about leadership. His courses differ from other similar courses by one essential factor: rather than merely lecturing about conducting, he gives the participants an opportunity to actually conduct professional choir singers. The participants' learning process is thus embodied, sensuous and performative, rather than cognitive and cerebral. The workshops are usually provided as part of broader executive education programs in various European business schools, and since the early 2000s they have shifted from being an oddity and a humorous warm-up exercise to being part of the core curriculum in these programs. At the beginning of each session, the participants are very quickly taught the basic hand movements to show the beat in conducting. They are then invited to conduct a small choir. Hanke helps them in the conducting task, and after the performance provides them feedback about their leadership style and approach. The participants' skills move quite fast on the collective learning curve, as more and more participants try conducting.

We have not ourselves acted as facilitators in choir conducting workshops, and therefore this chapter draws on our research on these workshops, not on our direct experience of using the approach. However, we have conducted a very careful and thorough data collection and analysis of these workshop and aim at sharing our findings and insights of this inspirational artistic method. We provide a thick description of these workshops, and then analyse how learning about leadership takes place in them. We draw on our observations of several workshops, on interviews with Peter Hanke and with a few participants, on official feedback materials collected after the workshops, and on Hanke's writings, website and blog. Our scientific world-view is based on social constructionism; we believe that reality and knowledge are created and maintained in ongoing processes of becoming between human beings, artefacts and objects. 
In our reading, there seem to be two distinctive characteristics that art-based interventions have in common. First, since they use methods and artefacts borrowed from the arts to produce an aesthetic experience, they are typically experiential, embodied, performative and emotional. In the case of art-based leadership development, managers are often invited to engage in an artistic activity, such as improvisation, design or acting, and their learning stems from this embodied experience. Second, art-based methods rely on analogical reasoning (Barry and Meisiek, 2010). Rather than learning by engaging directly with managerial and organizational tasks, participants are encouraged to engage with an analogical task or artefact. By viewing their day-to-day reality through the prism of the analogical medium, they gain new, transformative insights into this reality (ibid.).

Our analysis of Peter Hanke's conducting workshops, presented below, shows that experiential learning is a useful way of learning, and an embodied experiential learning, or sensuous learning, through an artistic method can bring about an even deeper occurrence of learning. More specifically, we show that an artistic method based on embodied agency and communication can be a powerful way to discover, learn and develop one's leadership behaviour. Our analysis also demonstrates the usefulness of analogical inquiry, by showing how the two very different analogical processes of choir conducting and managerial work are brought together in the workshops, generating new insights, ideas and embodied performances among the participants. We will explain how the analogical inquiry forces the participants out of their comfort zones in several ways, thus fostering a more powerful learning experience.

We also examine what message about the nature of leadership is conveyed in the workshops. We show how the workshops teach the participants that leadership is a balancing act between traditional notions of authoritative, heroic leadership and new egalitarian, post-heroic notions of leadership, and that it is their task to constantly navigate between these contradictory demands. Our study informs leadership theory by shedding light on the interesting negotiation between the old and new approaches to leadership present in these workshops. The relationship between the traditional, individualistic model of leadership and the new postheroic one may indeed be dialectic, not linear. The contributions to leadership development literature and to practicing managers themselves are in highlighting the significance of sensuous learning methods in the field of leadership education, as well as in highlighting the centrality of the ability to contain paradoxes and balance contradictions to leadership work. 


\section{Conceptual framing}

As early as 2002, Nissley described how organizations are beginning to integrate art-based learning approaches into management education. Nissley subsequently (2008) explained that management educators were criticized for not providing relevant education to leaders and managers who were coping with a rapidly changing and complex global business environment. Management education needed more elements of creativity and innovation, in addition to the traditional course content, and those skills could be learned from creative arts that typically existed outside of business schools. Nissley described how management educators began working in the intersection of arts and business and found art-based learning as an expressive means to create innovative and stimulating management education experiences. He illustrated how drama, visual arts, literary arts, dance and music are being deployed in various workshops and educational programs. Since then, more detailed empirical studies have been conducted about how particular artistic methods are deployed to teach leadership. Gayá Wicks and Rippin (2010) addressed the importance of experience in their study of an art-based leadership development session in which participants create dolls. Grisoni and Collins (2012) used poem houses - three dimensional artefacts combining visual interpretation with poetic text - to generate sense-making about individual and organizational experiences of leadership. Sutherland (2013) and Sutherland and Jelinek (2015, p. 301), who like us studied choir conducting workshops, explained that learning leadership happens "through the transformation of lived experience, more than rational-logical learning from texts, articles, and case studies" and that "the aesthetic comes to the foreground". In other words, these studies highlighted experiential learning and aesthetic ways of knowing. Taylor and Ladkin (2009) reviewed studies focusing on the use of art-based methods in managerial development, and identified four key processes through which learning takes place: skills transfer, projective technique, illustration of essence, and making. Most art-based methods include several of these four processes. Springborg (2012) conducted a systematic literature review to explore the unique contributions of art-based methods to management education. He concluded that the process of making and expressing more refined perceptual distinctions was the most essential common feature. 
We have chosen to use the notions of analogically mediated inquiry (Barry, 1994, Meisiek and Barry, 2007; Barry and Meisiek 2010) and experiential embodied performance to study the learning of leadership in choir conducting workshops. Analogically mediated inquiry comes very close to skills transfer and projective techniques, to use Taylor and Ladkin's (2009) categories, and it is also very similar to "associative work" that is used by Sutherland (2013). Embodied performance, on the other hand, bears resemblance to 'making', although it emphasizes the embodied, aesthetic ways of acting, knowing and learning and plays with the notion of performance. Performance is an interesting concept in relation to art-based methods and learning, which has perhaps not been addressed so often, although processes of performance are frequently mentioned in the literature.

\section{Analogically mediated inquiry}

The first to introduce the concept of analogically mediated inquiry was Barry (1994), who studied consulting processes in which participants are asked to create objects that represent aspects of their organizational life. He argued that the engagement with these material and embodied metaphors, or analogs, generates a collaborative process or exploration and experimentation. This conceptualization became all the more relevant as art-based initiatives became increasingly popular. Meisiek and Barry (2007, also Barry and Meisiek, 2010) have further elaborated on this framework and applied it to a variety of contemporary art initiatives, such as artist-in-residence programs, corporate art collections and organizational interventions led by choreographers, theatre directors, visual artists and musicians. In all these cases, Meisiek and Barry highlighted the capacity of analogical artefacts to shake taken for granted assumptions, shift perspectives and produce new, unexpected insights.

To understand the operation of analogically mediated inquiry, it is useful to examine how metaphors work. Metaphors involve a transfer of meaning from one semantic field or domain of content to another, so that the former domain (the source) maps and re-arranges to latter (the target), thus producing new meanings (Kittay, 1987). Constructivist theories of metaphor highlight their creative and generative character, and insist that they do not merely expose pre-given similarities between source and target domains, but also generate novel meanings and insights by juxtaposing these two domains (Ortony, 1979; Cornelissen, 2005). In analogically mediated inquiry, creative learning emerges by bringing an analogical artefact or activity to bear on participants' day-to-day concerns with management and organization. As 
explained by Barry and Meisiek (2010), analogical artefacts de-familiarize and destabilize participants' habitual understandings, and thus cultivate mindfulness, playful inquiry and reflection that is nevertheless relevant to participants' daily activities. When the analogical artefacts possess artistic attributes such as originality, subversion, deconstruction, redirection and symbolization, the effect is even more powerful (ibid.). As we will show below, the workshops we studied build precisely on this process, by bringing the analogical practice of choir conducting to bear on the participants' day-to-day managerial activities and identities, thus producing playful inquiry, reflection and learning.

\section{Embodied performance}

Another important characteristic of art-based methods is their focus on experiential and embodied performance and sensuous learning. Managers are accustomed to depend on verbal, cognitive and analytical skills, while they are less familiar with working with their emotions and bodies. Bodies and bodily performance - including physical stature, features, stance, gestures and voice - are central, yet often ignored elements in the accomplishment of leadership (Sinclair, 2005). Embodiment also means perceiving the world and creating knowledge through our five senses. This sense-based knowing, or sensuous knowing, is very typical of the artist's way of working. Therefore, as Taylor and Ladkin suggest (2009), artbased methods can provide a means of accessing and developing a different way of approaching the world and of generating knowledge, which in turn could contribute to a more holistic way of engaging with managerial contexts.

Taylor and Ladkin (2009, p. 56) use Heron's (1992) categories of "propositional knowing" and "presentational knowing". The first refers to knowing through ideas and theories, the latter means expressing meaning and significance through movement, dance, music, painting, poetry or drama. Accessing our embodied, sensuous knowing through presentational methods and forms rather than through propositional methods and forms is the distinctive characteristic of art-based methods. The presentational way of knowing is very similar to what we mean by embodied performance. The great benefit of presentational forms - or embodied performances - is that they provide relatively direct access to our felt experience and draw upon our emotional connection to self, others, and our experience. Propositional methods often filter out the feeling and emotion in pursuit of precision, clarity, and objectivity (Taylor and Ladkin, 2009, pp. 56-57). 
Embodied performance is a way to connect to emotions and feelings and mobilize the bodily knowledge as an important source of leadership. A leadership development workshop that builds on an embodied and non-verbal analogical activity is prone to bring managers out of their comfort zone, and facilitate a different way of learning leadership that yields deep, transformative realizations about one's self and one's leadership practice. The workshop can create a space for managers to experience safety in vulnerability (Antonacopoulou, 2014) and to reflect about their leadership practice. Despite being a one-time event, trying choir conducting can be a profound experience for the participating managers, and encourages them to engage in similar reflexivity in their leadership practice.

\section{Data collection and a description of choir conducting workshops}

This study focuses on conducting workshops that Peter Hanke delivers as part of a leadership training programme in a leading UK business school, the Saïd Business School, University of Oxford. The participants of the programme are senior executives, and it consists of lectures, group work and workshops, many of which are art-based. Unfortunately, we did not gain access to the entire programme, although the first author has sat through the sessions of one programme in 2007 and has an understanding of the content of the entire programme. Each workshop is a one-time group event of about two and a half hours. For this study, we conducted participant observations in nine workshops that Hanke delivered in 2009-2010. Four of them were part of the Oxford Strategic Leadership Programme at Saïd Business School and two were organized by Oxford Executive Education as part of customized programs for managers from two large financial firms. In addition, we observed three workshops that were less typical of Hanke's work: one workshop was organized independently by Hanke and a colleague of his, targeting professionals from the fields of media, communication and management consulting; two other workshops were offered to conducting students and were in a sense a mirror image of Hanke's usual workshops, since they brought managerial discourses to musicians rather than vice versa. However, all the workshops we participated in followed a similar structure.

In addition to the participant observations, we conducted semi-structured interviews by Skype or telephone with five managers who participated in Hanke's workshop as part of the Oxford 
Strategic Leadership Programme in 2012. We asked them to share their experiences, thoughts and feelings during the workshops. We also interviewed Peter Hanke himself three times to discuss his ideas on art-based leadership training and his own experiences during the sessions we had observed. Hanke's writings $(2005,2008)$ as well as his website, blog and advertising material from Saïd Business School (video clip 3) provided further information on his views. A few of his workshops are also video-recorded and available on Youtube (video clips 1 and 2). Finally, we were allowed to use the official feedback questionnaires on Hanke's workshops that Saïd Business School had collected between 2008-2012. This feedback material includes both quantitative ranking - the workshops are consistently rated very high but also short verbal comments provided by the participants. We analysed the data through several rounds of reading, coding and comparison between the different sessions we had participated in.

As noted above, all the workshops we observed have a similar structure. Many workshops take place in beautiful old college chapels. The choristers sing a classic English choral repertoire. The setting creates a peaceful atmosphere that further underlines the fact that we are presently engaging in something unfamiliar and different. It also helps produce "a sense of privilege, awe and fun" according to one participant (feedback material, 2008). Typically, 2025 managers participate in one workshop, which follows a rather strict structure. Peter Hanke first talks very shortly about what managers can learn from the arts and from music in particular, but fairly quickly he moves to the activity itself. The managers and choristers are asked to intermingle, find pairs and try to shadow each other's movements. This allows them to practise leading and following in a very elementary way. Hanke then teaches managers the basic hand movements of a conductor - the showing of beat and phrasing.

The managers and choristers are next instructed to sit down, the choristers are sitting among the managers in a random order. Hanke then asks for the first volunteer to stand up and conduct the singers. It takes much courage to be the first one to try out conducting in front of Hanke, the professional singers and peers in the course, but it is also tempting, and a volunteer always emerges. The choristers are instructed to sing exactly as the manager conducts with his/her hand movements and gestures. Hanke watches for a while, congratulates the 'conductor', inquires about her or his experiences, and proceeds to share his observations of the participant's leadership style and dilemmas. The participant then gets to try again and improve with the help of Hanke's comments, and sometimes also with the help 
of his hand, as he holds the participant's hand and conducts with it. Almost everyone wants to experience conducting; one after another the participants step up and try the conducting exercise. The atmosphere is rather relaxed after the early tension is released, and there is a lot of laughter and displayed emotions. The Youtube videos (video clips 1 and 2) provide a very nice illustration of the content and nature of Hanke's workshops.

\section{Process of learning}

In this section, we describe the learning processes that take place in the studied choir conducting workshops. We do this by examining first how analogically mediated inquiry produces learning in the workshops, and then how embodied performance does so. Of course, the learning processes in these intense and condensed workshops occur simultaneously, and the distinction is only made for the analytical purposes of our discussion.

\section{Analogically mediated inquiry}

The studied conducting workshops bring together two analogical practices that are seemingly very different - business management and choir conducting. While management is typically perceived as a rational, cerebral, verbal and disembodied activity (Sinclair, 2005), musical conducting is a primarily non-verbal, embodied activity that builds on emotional and aesthetic qualities. Furthermore, while managerial practices are typically dispersed in time and space, conducting involves immediate interaction in the same time and space continuum. Nevertheless, it is precisely this difference between the two activities that generates defamiliarization and re-framing, and that makes the analogically mediated inquiry effective.

In the workshops, participants are encouraged to explore the 'source field' of choir conducing to generate new insights and understandings on the 'target field': business management. Peter Hanke as the facilitator has the key responsibility of helping the participants to notice the analogies between conducting and business leadership and elaborate on them. He talks about the style, speed and timing of the participants as they conduct, and relates these features to the participants' work as managers. For example, he associates a conductor's beat with decision making, and explains how slow tempo means hesitant or insecure decision making while fast tempo equals quick decision making. Contemporary workers, many of which are experts and 
knowledge workers, appreciate timely decisions from their leaders, which enable them to carry on their work, whereas slow decisions are frustrating. "Knowledge workers need light and speedy decisions, a flow. Slowness is stressful, not relaxing" (fieldnotes). Slow decisions may also indicate the leader does not trust his or her followers despite they being experts, and is inclined towards drowning in details and micro-management. "You have to make decisions just a little bit before you feel comfortable. That happens in business every day" (fieldnotes).

Indeed, the contrast between delving in details and seeing the big picture is another example of Hanke's analogies; he advises the conducting managers to grasp the big picture and trust the experts to handle the details. Some participants are told that they are too authoritative and adviced to relax a bit and trust the experts' knowledge. The following quotation from an interview with a participant gives an example of Hanke's use of the notions of big picture vs. orientation to details:

"The other thing I thought was amazing was his ability to pull out analyses or insights into their [the participants'] leadership styles from the way that they conducted. So for example, there was one girl who was very airy-fairy, not particularly, you know, not particularly paying attention to what the singers were doing, and he made the point to her that you manage kind of on your own wave length, and you kind of got the big picture, you worry about the big picture but you don't really worry about anything else. And she said that's absolutely right.

Whereas there was another guy who was conducting almost with his fingers, reallyreally small, and he said to this guy, you're like a details person, get away from the details, get out of the grass, get out of the grass and the weeds, and come up and let them work as a team and let them, you know, sing. And he asked him, you know, "is that what you're like?", and he said "Yes, I'm a complete micro-management details guy". So it was very interesting that he could peak that observations about their leadership style from the way they conducted" (Julia, senior executive in a financial corporation).

Many of Hanke's analogies surround the topic of leading experts - apparently a common dilemma for many participants. Several participants are instructed to trust their "employees", that is, the choristers, since they are the experts. Sometimes Hanke tells the participant that s/he should take a step back, kiss goodbye to her/his career as an expert, and fully embrace the role of a leader. Hanke explains how this exercise is an extreme example of a situation in 
which the experts know everything and the manager knows nothing, since the participants have no knowledge of conducting nor of the performed music, and the choristers are professional singers. According to Hanke, this is often the case in business organizations too, and an important skill for leaders is to be able to lead and inspire experts even in such extreme situations. In his words: "This would be daily life experience that you have to reach out and understand expertise, skilled people's contribution, and take decisions based on something you don't know very well yourself" (video clip 3).

According to our analysis, Peter Hanke's comments and instructions, as well as the very analogy between conducting and business leadership, convey specific messages about what is considered good leadership and good leaders. We found that the workshops evoke two models of the good leader simultaneously: an egalitarian, sharing and empowering model on the one hand and an authoritative, heroic and romantic model on the other hand. The former, post-heroic leadership model (Fletcher, 2004) is clearly more dominant in the workshops; the latter, heroic model of leadership is more implicit, yet nevertheless present. The key message is that participants have to learn to balance these contradictory needs in their leadership approach. This is a rather elegant, yet demanding message, and the conducting exercise with its experiential elements is a well-suited medium for conveying this message.

Balancing the contradiction means, for example, that the participants are expected to lead but also be led, be in control but also surrender control, be attentive to the rules but also be playful, plan but cherish the flow of events, broadcast but also listen, see the big picture but also the small details, etc. Table 1 presents the variety of tensions and paradoxical demands that we identified in the workshops and that the participants are expected to balance between. The left column presents aspects of heroic leadership and the right column aspects of postheroic leadership.

\begin{tabular}{|l|l|}
\hline Aspects of heroic leadership & Aspects of post-heroic leadership \\
\hline Authoritative, decisive, centralistic & Empowering, sharing, inviting the ensemble \\
\hline Taking control, being in control & Surrendering control \\
\hline $\begin{array}{l}\text { Keeping distance from the ensemble, } \\
\text { detached, protected }\end{array}$ & $\begin{array}{l}\text { Standing close to the ensemble, open, } \\
\text { vulnerable }\end{array}$ \\
\hline Confident, knowledgeable & Uncomfortable, humble, acknowledging \\
\hline
\end{tabular}




\begin{tabular}{|l|l|}
\hline & choristers' expertise \\
\hline Focusing on expressing, broadcasting & Focusing on perceiving, sensing \\
\hline Rational & Emotional, passionate, intuitive \\
\hline Cerebral, intellectual, verbal & Embodied, non-verbal \\
\hline Focusing on details, analytical & Seeing the big picture \\
\hline Thinking, planning, reflecting & Doing, being 'in the moment' \\
\hline Working according to the rules & $\begin{array}{l}\text { Creatively improvising, playfully } \\
\text { experimenting }\end{array}$ \\
\hline Slow & Fast \\
\hline Heavy, steady, muscular, laborious & Light, flowing, flexible \\
\hline
\end{tabular}

Table 1. Contradictory leadership demands

The heroic model of leadership conveyed in the workshop stems largely from the very figure of the conductor, as it is perceived in popular culture. This figure is heavily laden with heroic, authoritative and "masculine" leadership attributes. Although contemporary conductors sometimes apply a more egalitarian and empowering approach to their leadership work, traditionally conductors are considered very imposing figures, who make all the decisions and keep distance from the musicians. Management textbooks often use the conductor as an example of a manager who has everything under firm control and who plays the orchestra as one big instrument. The art world and the general public consider successful artists such as conductors to be exceptionally talented persons, thus perfectly endorsing the myth of individual artistic genius. Consequently, these aspects of strong individual-based leadership are inherently present in the studied conducting workshops. It must be very compelling to step into the shoes of a conductor and try out that task oneself. It is indicative that nearly all the managers in Hanke's workshops, even the most shy, sceptical or hostile, are eventually tempted to volunteer and conduct. For some, this proves to be an exhilarating experience:

I wanted to do it, but my stomach was turning, I felt absolutely scared stiff, because we were on show in front of everybody. And I worried in case I got it wrong, because I don't really like doing that. So I was nervous, really-really nervous. $[\ldots]$

Question: And then how did you feel when you did the conducting itself? 
Oh, I absolutely adored it. I really loved it. It felt... I just felt exhilarated. And I felt it was great.

Question: Why do you think, why do you think it was so pleasurable?

Oh...their singing was exquisite, and the acoustics in the chapel were amazing, and I enjoyed it because I have done something I had never done before, and I felt as if I had achieved something. [...] One time I sort of put my hand up, and sort of did that [makes a gesture], and they all did it! You know, it was just lovely, it was wonderful. It was one of the best experiences I ever had. It will live with me forever" (Anne, senior manager in a public-sector organization).

Parallel to the evocation of the heroic leadership model, many other elements in the workshops sanction an egalitarian, open and sharing approach to leadership. As mentioned above, Hanke frequently reminds participants that it is the choristers who are the "true experts', not them, and thus sanctions a humbler and reciprocal form of leadership. He also often encourages participants to cede some of their control over the situation and hand it to the ensemble, to negotiate with the choristers, and to 'invite' them to the music making as if they were offering them a gift. These comments emphasize a leadership approach that is open, transparent and sharing, and humbly acknowledges the creativity and expertise of the subordinates. Take this example, described in our fieldnotes:

A middle-aged, healthy looking guy volunteers to conduct. His conducting style is very decisive, very commanding, also very fast - which passes as quite inconsiderate, since the singers find it difficult to follow him. After he finishes, Hanke asks him: "Are you in control?" The man hesitates. Hanke then asks the audience: "Is he in control?" Then he continues, smiling: "Very much in control!" [People laugh]. "He makes too many decisions!" Then Hanke turns to the man again: "Do you work hard?" The man answers that he does. Hanke then comments about the prevalent tendency to work too hard, to make too many efforts, to micromanage the details and consequently lose sight of the big picture.

At a later stage, Hanke asks the man if he can try to conduct again, but this time invite the singers. The man performs another musical piece, after which Hanke says: "Very interesting change. This is invitation. You invite them to be with you." The man responds: "Yes, letting go a bit of the cerebral cortex over there" [points to the back of his head]. And Hanke comments: "This invitation is for me the virtuous base of music." 
Our general impression is that while Hanke instructs insecure male and female participants to assume a more assertive and authoritative posture, he frequently instructs male participants with too 'militant' a style to soften their masculine bodily performance, i.e. to adjust their posture to the unassuming, post-heroic ideal.

Another expression of the post-heroic model occurs when Hanke advices participants to 'forget about themselves' and concentrate on their followers and on the organization. This is clearly one of the paradoxes too, since one needs to have enough self-confidence and ability as a leader to fully be able to concentrate on one's followers. One needs to do both, but not too much, and not too little. Again, the participants are instructed to trust their sensuous perception and judgment and be 'in the moment' together with the ensemble. The following Youtube video, which records a workshop organized jointly by the University of Oxford and the African Leadership Institute, (Video clip 2) includes an example of Hanke's advice to participants to concentrate on their followers, and not only on themselves:

The video shows a woman conducting. The narrator's voice explains that "keeping pace with creative and independent-minded business woman Swadi can be a challenge". She conducts in a rather slow and occasionally uneven beat. Hanke notes: "You feel at home here, don't you?" Swadi: "Yes, definitely". Hanke: "Interesting. So you are having a great time?" Swadi: "Yeah, yes." Hanke: "That is great ... for you." [Laughter from the participants]. "Can you also make your organization have a great time? We are lacking something that may also be a little challenge for you; consistency in your decisions. Boring consistency and predictability might help; it can be quite useful and liberating for the organization". Swadi starts conducting again and Peter helps by holding her hand and showing an appropriate pace in hand movements. Swadi then continues to conduct on her own and manages to keep the good pace in her beat. Hanke: "See, it did not become boring at all!"

\section{Embodied performance}

The descriptions of the participants trying out conducting in the previous sub-section include an abundance of examples of embodied performance and its elements. We identified the following elements in the workshops: non-verbal communication, performing in front of 
others and being bodily exposed, learning to tap into sensuous perception and emotions, and enduring tensions and risks. In this sub-section, we discuss these features in more detail.

When trying out the conducting exercise, the participants have to engage in non-verbal communication to deliver their message. This is rather contrary to their day-to-day managerial work, which usually involves verbal communication: expressing oneself with spoken and written language. Most managers are very fluent speakers and accustomed to influence and inspire their employees by talking. Consequently, expressing oneself via hand movements, gestures and facial expressions only is a completely new situation for the participants. They are required to "make decisions with their hands", as Hanke puts it, in order to connect with their followers and their organization.

Since the participants are so clearly out of their comfort zone in this exercise and cannot control the situation, they reveal a lot about their leadership behaviour to a trained observer, such as Peter Hanke. The participants are unprotected and vulnerable. Many participants find this experience embarrassing and unsettling, and some of our interviewees recounted that they were hesitant to volunteer and perform, and considered avoiding the task altogether. They viewed their decision to take the risk and perform as an achievement in itself, indicative of their capabilities and courage as managers:

"If I had been on my own there, with the choir, I would have felt more comfortable doing it. But doing it in public, learning like that, or testing your boundaries in public, I was really reluctant to do it. So, I was one of the last ones to do it, because I wanted to see how everyone else did it.

But I did learn that... the fact that I was reluctant to go up and do it... I really should have just at the outset said, yeah, I'll give it a go, I should have been a bit more assertive. And maybe as a leader I need to be a bit more assertive and say, yeah, I'll do that." (Julia, senior executive in a financial corporation)

In a way the conducting exercise becomes a test, or an ordeal, that the manager must endure in order to prove him/herself in front of his/her peers and of Peter Hanke. And this ordeal is very embodied in nature. 
Furthermore, the participants are encouraged to trust the flow of events in the workshop, to trust the process. This appears to emphasize the sensuous perception and emotions more than cognitive thinking. The participants are invited to go with the flow of events, communicate and react with their bodies. The process is so rapid that there is no time to stop for thinking or reflecting; one has to trust one's abilities and plunge into the unknown territory. This is highlighted by one of Hanke's comments recorded in our fieldnotes: "This is another interesting paradox of leadership; when you reflect on things, when you become conscious, you have to slow down and then you're no longer in the business". This comment does not suggest that managers should not think or rely on their cognitive skills; rather, it stresses the role of sensuous perception and the wisdom of the body. The participating managers are encouraged to make use of their emotions and instincts when exercising leadership and making practical judgments in their daily work.

The embodied nature of the workshop, and the request that the participants jump into unknown territories in a very concrete manner, convey the idea that management is about taking risks and about being able to perform in the most extreme situations. Even though Hanke acknowledges the courage required for volunteering to conduct and thanks the volunteers for their bravery, he also notes that a leader should always "have something at stake", always maintain tension and alertness in her performance, always "be there" and never "avoid the leadership situation". In other words, he portrays conducting - and management by implication - as a precarious performance that requires permanent risk-taking and permanent tension. While one may have an urge to escape the performative predicament, one must never surrender to this urge.

To conclude this section, we combine the two leadership dispositions that are promoted in the workshops - the capacity to hold contradictory demands and the capacity to engage in risky public performance. When these two dispositions are merged together into one managerial persona, it appears that the most fitting metaphor for this persona is that of a tightrope artist. Like a tightrope artist, the manager - as he or she is portrayed in these workshops - is required to balance various tensions in front of a watchful audience and under the constant, petrifying risk of a fall. Moreover, this risky performance is construed not only as a means to an end, but also as a bearer of aesthetic and ethical values. Both these sources of creative and aesthetic tension are captured in the next short text, which Peter Hanke posted on his website. 


\section{Uncomfortable, yet confident}

A part of the inspirational mindset is to dare stay uncomfortable, as the role of the conductor with lesser knowledge than the singers, clearly marks - and at the same time raise the confidence in this situation. You become a true spokesperson for inspiration by constantly having something at stake and never really leaning back and relaxing.

From a first impression this appears like a completely stressed out situation, but the clue is to find where to include the singers - the organization - and make the vulnerability become an exploratory and honest place to be for all.

The conductor becomes a living role-model for daring experiments and courageous steps into the unknown.

\section{Evidence of impacts}

In the previous section, we have presented and analysed learning processes that we had observed in the workshops and considered important. In this section, we share evidence from our interviews with participants and from their feedback notes, and illustrate how they described their take-away and learning from the conducting workshop. We identified three themes that were mentioned often: receiving insightful comments about one's leadership style; learning how one copes in unfamiliar situations; and understanding the obligation to tune into your employees' needs, while maintaining the ability to act decisively.

The experiential and embodied nature of the workshops affected the type of learning reported by the participants. Rather than obtaining cognitive, abstract and detached knowledge, participants acquired knowledge about their selves and their communication with others. Many participants were highly impressed by Hanke's ability to make observations about them and about other participants, and to offer suggestions with regard to their leadership style and dilemmas, as the following citations reveal:

"The other thing I thought was amazing was his [Peter's] ability to pull out analyses or insights into their leadership styles from the way that they conducted." (Julia, senior executive in a financial corporation) 
"I found the leadership insights offered to myself and all the participants by Peter inspirational and insightful." (feedback notes, 2011)

“What struck me was Peter's comments, not just to me but to everybody based on that short 30 seconds of observations, I don't even know if it is 30 seconds or not, but he seemed to build a base on that short period of observations, either based on body language or eye contact or whatever. He just picked up a couple of things which I thought was fascinating. You know, that this thing does reveal something about your personality and your leadeship style. He said something about me that I thought was quite spot on." (Robert, senior executive in a financial corporation)

Peter Hanke himself analysed the typical learning outcomes of the participants in similar terms, in an advertising video for the Oxford Strategic Leadership Programme (video clip 3):

A typical reaction when people walk out of this exercise is that they get x-rayed a bit deeper than they normally would in this sort of session. We have trained ourselves, both me and the musicians, to be very clear in our observations and message about preferences, instincts, leadership take on things - whether you take charge or are reluctant - all these different aspects of your leadership shine through in a way that you rarely feel. [...] People say 'oh this was clarifying, this was opening up for a different conversation with myself because now I get a very clear picture of who I am and how I ignite my own passion'.

The managers also found useful the possibility to practise a situation in which one has to perform under completely new circumstances. This aspect of their learning is related to the analogically mediated inquiry that takes place in the workshops. As we have argued in the previous sections, the analogical nature of the workshops requires participants to perform in a completely new medium that is nevertheless relevant to their daily lives, and this takes them out of their comfort zone and provides them with fresh insights into familiar aspects of their selves and realities. Participants could notice the similarity between the need to cope with the unfamiliar task of conducting and many situations in their work, for example, the reality of starting in a new company: 
"It was a useful session because it is a practical approach of how you react in an unknown situation. Let's say that tomorrow you will be appointed as a boss of this department in a new company. So you have never been in the company and suddenly you are the boss, how would you handle it? " (David, senior director in a government institution)

"Way outside my comfort zone but a really positive lesson in the out of the possible" (feedback notes, 2011)

Many participants also pointed out that they now see more clearly that - as leaders and managers - they have to tune into their employees' needs and concerns, while at the same time remaining decisive and assertive. This learning point is related the central message about leadership that we have identified in workshops - that a good leader should be able to balance between authoritative, heroic leadership and egalitarian, post-heroic leadership. This understanding is reflected, for example, in the following quotations:

"As a personal experience, this was the highlight of the week for me! In terms of relevance, it certainly made me think hard about when to practise 'active' leadership and when to let people lead themselves." (feedback notes, 2008)

"It's about being... I would say the similarity is about being tuned in to what other people's needs are. And it's about also being able to take them where you want them to go. And I didn't think I could do that in music at all, because I'm not musical, but... But actually the similarity does go across in my job. So I do see that." (Anne, senior manager in a public-sector organization)

"The lesson I learnt is about how you should be responsive to others. And it's about their needs, not yours. And controlling them, if you like, or being in command of them, is actually about doing the best for them, not for yourself, I think. So it's about convincing them that they can actually be empowered enough to take their journey to the next step. " (Anne, senior manager in a public-sector organization)

These and similar statements made by some of the participants demonstrate, we believe, that they understood the message conveyed in the workshops, that leadership is a dialectical and 
paradoxical task. It appears that at least some of the participants experienced in their bodies the idea that was transmitted in the workshops and that we have analysed theoretically: a good leader should be able to demonstrate both heroic and post-heroic leadership, and the relationship between these two modes of leadership is dialectical, not linear.

\section{Lessons learnt}

The choir conducting workshops we studied demonstrate how participants can learn many things about leadership and about themselves, and even reach deep realizations, during this rather short exercise. Therefore, we believe the power of these experiential workshops, which require participants to throw themselves into cold water and try conducting professional singers, is considerable. We also think the workshop is suitable for managers at different levels: from team leaders to senior executives.

One limitation of choir conducting workshops as an art-based method is that it is not easily accessible to management educators and facilitators. The facilitator needs very high professional skills in music and choral conducting as a starting point. In addition, the ability to work with analogically mediated inquiry that juxtaposes choir conducting and business management is yet another skill that easily takes years to develop. Peter Hanke noted (video clip 1) how he and the choral singers had worked for almost ten years to perfect their skills in observing and commenting on workshop participants' leadership performance. Indeed, we noticed that the participants were impressed by Hanke's diagnostic skills. It is difficult to estimate to what extent a less experienced choir conductor would be able to evaluate participants' performance in a similar setting. It is also difficult to assess whether another conductor would be as successful in bringing the world of conducting to bear on the world of management.

Another limitation of this workshop is shared by all art-based methods: the participants might not take it seriously, or they might fail to see the connection to their daily work. Despite the increased use of art-based methods, some participants may still feel alienated by such approaches and fail to embrace the learning offered by them. They either feel they lack the necessary creativity, or they are incapable or reluctant toward analogical thinking. 
One definite advantage of choir conducting workshops is that the participants receive instant feedback on their performance from their followers, the singers. That hardly ever happens in their daily managerial work. Furthermore, this human encounter is very aesthetic and sensuous in nature since it builds on an embodied interaction. The managers receive a very concrete experience of human interaction with the singers: the ability to inspire others, feel their humanity and touch their aspirations. It creates a profound experience and emphasizes how leadership goes way beyond the realm of cognitive thinking.

In addition to encouraging learning about leadership performance, choir conducting workshops could certainly be beneficial to learning about team-building, collaborative skills and followership. The workshops highlight in a very beautiful manner the importance of relational skills, of blending in and tuning into other people's emotional spirit. When conducting a choir, and also when singing in a choir, one receives instantaneous feedback about being in tune - or out of tune. Perhaps singing in a choir could be the next art-based method leadership educators could develop.

\section{References:}

Antonacopoulou, E. (2014). The experience of learning in space and time. Prometheus, 32(1), 83-91.

Austin, R., Devin, L. (2003). Artful creation. What managers need to know about how artists work. New Jersey: Prentice Hall.

Barry, D. (1994). Making the invisible visible: Symbolic means for surfacing unconscious processes in organizations. Organizational Development Journal, 12, 37-48.

Barry, D., Meisiek, S. (2010). Seeing more and seeing differently: Sensemaking, mindfulness, and the workarts. Organization Studies, 31, 1505-1530.

Cornelissen, J.P. (2005). Beyond compare: Metaphor in organization theory. Academy of Management Review, 30, 751-764.

Darsø, L. (2004). Artful creation: Learning-tales of arts-in-business. Fredriksberg: Samfundslitteratur.

Day, D.V., Fleenor, J.W., Atwater, L.E., Sturm, R.E., McKee, R.A. (2014). Advances in leader and leadership development: A review of 25 years of research and theory. The Leadership Quarterly, 25, 63-82. 
Fletcher, J.K. (2004). The paradox of postheroic leadership: An essay on gender, power, and transformational change. Leadership Quarterly, 15, 647-661.

Gayá Wicks, P., Rippin, A. (2010). Art as experience: An inquiry into art and leadership using dolls and doll-making. Leadership, 6(3), 259-278.

Grisoni, L., Collins, B. (2012). Sense making through poem houses. An arts-based approach to understanding leadership. Visual Studies, 27(1), 35-47.

Hanke, P. (2005). Kreativitet kan ikke anskaffes - det skal læres. Ledelse i Dag, 61, 32-36.

Hanke, P. (2008/2013). Performance and leadership. Translated excerpts from Performance \& lederskab: Passionen som drivkraft. Børsens Forlag.

Heron, J. (1992). Feeling and personhood. Psychology in another key. London: Sage.

Johansson Skoldberg, U., Woodilla, J., Berthoin Antal, A. (Eds.) (2015). Artistic interventions in organisations. Research, theory and practice. Abingdon and New York: Routledge.

Kark, R. (2011). Games managers play: Play as a form of leadership development. Academy of Management Learning \& Education, 10, 507-527.

Kittay, E. (1987). Metaphor: its cognitive force and linguistic structure. Oxford, New York: Clarendon Press Oxford University Press.

Koivunen, N., Wennes, G. (2011). Show us the sound! Aesthetic leadership of symphony orchestra conductors. Leadership, 7(1), 51-71.

Meisiek, S., Barry, D. (2007). Through the looking glass of organizational theatre: Analogically mediated inquiry in organizations. Organization Studies, 28, 1805-1827.

Nissley, N. (2002). Arts-based learning in management education. In R. DeFillippi, C. Wankel (Eds.), Rethinking management education for the $21^{\text {st }}$ century (pp. 27-61). Greenwich, CT: Information Age Publishing.

Nissley, N. (2008). Framing arts-based learning as an intersectional innovation in continuing management education. The intersection of arts and business and the innovation of arts-based learning. In C. Wankel, R. DeFillippi (Eds.), University and corporate innovations in lifelong learning, (pp. 187-211). Charlotte, NC: Information Age Publishing.

Ortony, A. (1979). Metaphor, language and thought. In A. Ortony (Ed.), Metaphor and thought (pp. 1-16). Cambridge: Cambridge University Press.

Parush, T., Koivunen, N. (2014). Paradoxes, double binds, and the construction of 'creative' managerial selves in art-based leadership development. Scandinavian Journal of Management, 30, 104-113.

Sinclair, A. (2005). Body possibilities in leadership. Leadership, 1(4), 387-406. 
Sinclair, A. (2011). Being leaders: Identities and identity work in leadership. In A. Bryman, D. Collinson, K. Grint, B. Jackson, M. Uhl-Bien (Eds.), The Sage Handbook of Leadership Studies (pp. 508-517). London: Sage.

Springborg, C. (2012). Perceptual refinement: Art-based methods in managerial education, Organizational Aesthetics. 1(1), 116-137.

Strati, A. 1999. Organization and aesthetics. London: Sage.

Sutherland, I. (2013). Art-based methods in leadership development: Affording aesthetic workspaces, reflexivity and memories with momentum. Management Learning, 44, 25-43.

Sutherland, I., Jelinek, J. (2015). From experiential learning to aesthetic knowing: The arts in leadership development. Advances in Developing Human Resources, 17(3), 289-306.

Taylor SS, Hansen H (2005). Finding form: Looking at the field of organizational aesthetics. Journal of Management Studies, 42(6), 1211-1231.

Taylor, S.S., Ladkin, D. (2009). Understanding arts-based methods in managerial development. Academy of Management Learning \& Education, 8(1), 55-69.

Warren S (2008). Empirical challenges in organizational aesthetics research: Towards a sensual methodology. Organization Studies 29(4), 557-580.

\section{Web pages:}

Video clip 1. Resetting the Business Agenda: Leadership as Performance, Saïd Business School, University of Oxford, https://www.youtube.com/watch?v=M6swU4iKuwU, Published on October 30, 2012

Video clip 2. Exart Performances with the African Leadership Institute, https://www.youtube.com/watch?v=WGJb4 fQBcc, Published on September 13, 2013

Video clip 3. Oxford Strategic Leadership Programme: Learning from performance, Saïd Business School, University of Oxford, https://www.youtube.com/watch?v=gT4r1OaiNWc, Published on March 24, 2016

www.performingleadership.blogspot.com Accessed 13.1.2013 